\title{
Mycobacteriophages to Treat Tuberculosis: Dream or Delusion?
}

\author{
Andreas H. Diacon ${ }^{a}$ Carlos A. Guerrero-Bustamante ${ }^{b}$ Bernd Rosenkranz ${ }^{c, d}$ \\ Francisco J. Rubio Pomar ${ }^{\mathrm{e}}$ Naadira Vanker ${ }^{\mathrm{a}}$ Graham F. Hatfullb \\ aTask Applied Science, Cape Town, South Africa; ${ }^{b}$ Department of Biological Sciences, University of Pittsburgh, \\ Pittsburgh, PA, USA; 'Division of Pharmacology, Stellenbosch University, Cape Town, South Africa;

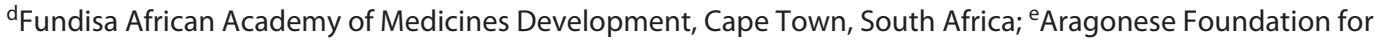 \\ Research \& Development, Zaragoza, Spain
}

\section{Keywords}

Tuberculosis · Bacteriophages · Antimicrobial resistance

\begin{abstract}
Rates of antimicrobial resistance are increasing globally while the pipeline of new antibiotics is drying up, putting patients with disease caused by drug-resistant bacteria at increased risk of complications and death. The growing costs for diagnosis and management of drug resistance threaten tuberculosis control where the disease is endemic and resources limited. Bacteriophages are viruses that attack bacteria. Phage preparations served as anti-infective agents long before antibiotics were discovered. Though small in size, phages are the most abundant and diverse biological entity on earth. Phages have co-evolved with their hosts and possess all the tools needed to infect and kill bacteria, independent of drug resistance. Modern biotechnology has improved our understanding of the biology of phages and their possible uses. Phage preparations are available to treat meat, fruit, vegetables, and dairy products against parasites or to prevent contamination with human pathogens, such as Listeria monocytogenes, Escherichia coli,
\end{abstract}

or Staphylococcus aureus. Such phage-treated products are considered fit for human consumption. A number of recent case reports describe in great detail the successful treatment of highly drug-resistant infections with individualized phage preparations. Formal clinical trials with standardized products are slowly emerging. With its highly conserved genome and relative paucity of natural phage defence mechanisms Mycobacterium tuberculosis appears to be a suitable target for phage treatment. A phage cocktail with diverse and strictly lytic phages that kill all lineages of M. tuberculosis, and can be propagated on Mycobacterium smegmatis, has been assembled and is available for the evaluation of optimal dosage and suitable routes of administration for tuberculosis in humans. Phage treatment can be expected to be safe and active on extracellular organisms, but phage penetration to intracellular and granulomatous environments as well as synergistic effects with antibiotics are important questions to address during further evaluation.

(c) 2021 S. Karger AG, Basel

From the Thematic Review Series: "Tuberculosis"

Series Editors: Coenraad F. Koegelenberg, Christoph Lange, Otto D. Schoch.
Correspondence to:

Andreas H. Diacon, ahd@ task.org.za 


\section{Introduction}

\section{Tuberculosis}

Tuberculosis (TB) has troubled humanity for millennia. More than 9,000 years ago Mycobacterium tuberculosis (MTB) evolved from environmental ancestors to a strictly human pathogen adapted to peaceful intracellular life. Less than one in 10 latently infected individuals develop active pulmonary tuberculosis during a lifetime and spreads extracellular organisms to a new host via expectorated airborne droplets [1]. Active TB disease has variously been known as consumption, phthisis, or the white plague $[2,3]$. In the 18 th century, TB was responsible for the death of every 4 th person in Western Europe and the USA. Improving living conditions and the discovery of its bacterial cause in the late 19th century was followed by medical progress with diagnostics, vaccines, and treatments. Though incidence rates have declined slowly over recent years, it should be remembered that we are nowhere near victory over TB, which still lies dormant in a quarter of the world's population [4]. Increasing rates of drug resistance and infection with the human immunodeficiency virus threaten control of the TB epidemic in areas of high prevalence.

\section{Antimicrobial Resistance}

Increased risk of poor clinical outcomes are well known for patients infected with problematic multi-drug resistant organisms, such as Enterococcus faecium, Staphylococcus aureus, Klebsiella pneumoniae, Acinetobacter baumannii, Pseudomonas aeruginosa, and Enterobacter species [5]. Poor chances of compound success and skyrocketing costs of drug discovery and development have dried up the pipeline for new antibiotics. Health policies aiming to reduce antibiotic use in both humans and livestock can only delay, but not stop, the increase in antimicrobial resistance (AMR). The World Health Organization (WHO) and the UK Government warn that increasing AMR threatens the effective prevention and treatment of an ever-increasing range of infections caused by bacteria, parasites, viruses, and fungi that could result in 10 million deaths yearly by $2050[6,7]$.

\section{$A M R$ in $T B$}

The history of TB drug resistance started in 1948 with the very 1st controlled clinical trial that used streptomycin monotherapy [8]. After initial improvement with treatment many patients deteriorated and were later found to have acquired streptomycin resistance [8]. $M$. tuberculosis acquires drug resistance by spontaneous chromosomal mutation that provides a survival benefit in the presence of therapeutic antibiotic concentrations. These mutations are passed on to the next generation of mycobacteria that, in time, can acquire multiple mutations conferring resistance to many, in some cases virtually all available antimycobacterial agents [9]. The WHO estimates that, in 2019, there were 10 million new TB cases and 1.4 million TB deaths [10]. Resistance to rifampicin, the cornerstone agent, was found in 3.3\% of new cases and in $18 \%$ of those previously treated amongst whom even more extensive resistance was expected in every 10 th case. Drug resistance rates rising by $>20 \%$ annually have met with increasing scientific interest leading to a better understanding of its underlying mechanisms (online suppl. Fig. S1; see www.karger.com/doi/10.1159/000519870 for all online suppl. material) [10]. Latent infection with rifampicin resistant MTB has recently been estimated to be prevalent in 3 out of every 1,000 adults but also in 3 out of every 100 persons younger than 15 years. This proportion is likely to increase, which poses serious challenges for management of latent tuberculosis as a strategy for TB elimination $[11,12]$.

\section{Bacteriophages}

\section{Discovery and Early History}

Bacteriophages were first described by Frederick Twort (1915) and Felix d'Hérelle (1917), who independently described small infecting agents of unknown nature that would make cultured bacteria disappear [13]. Bacteriophage (from Greek: bacteria-eater) was a suitable name at the time considering that phages were invisible. Electron microscopes were only developed in the 1930s [14]. D'Hérelle, of whose interesting career Dublanchet [13] gave a colourful account in a lecture in 2004, first used phages isolated from the stool of patients recovering from dysentery, to treat dysentery. Phages active against multiple other pathogenic bacteria, such as Neisseria meningitis, Salmonella typhi, Shigella dysenteriae, Vibrio cholerae, and Yersinia pestis were soon discovered and also used for treatment of these conditions.

The "golden age of phage therapy" lasted from the 1920 s to the 1950 s when effective antibiotics with a much wider spectrum almost completely replaced phage treatments. Until modern biotechnology emerged, little was known about the interaction between phage and host strains so that treatment was "hit and miss" at best. Phage technology survived in Eastern Europe where phagebased products remain available to this day in familiar 


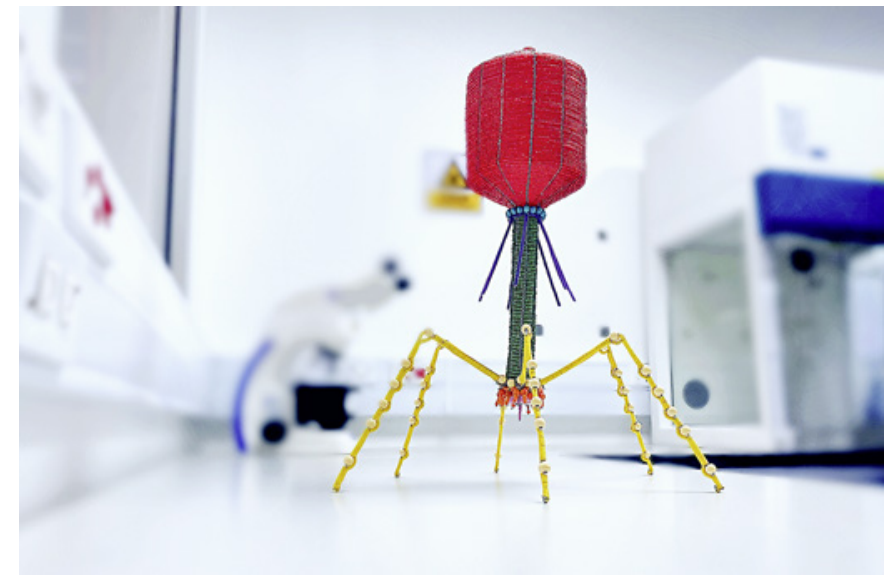

Fig. 1. Phage morphology. An artefact of a representative tailed mycobacteriophage with a proteinaceous head (capsid, red) that encloses and protects the genome inside it. The collar (blue beads) and whiskers (purple spikes) connect to the tail sheath (green) that is contractile in some phages (Myoviridae). The baseplate (orange) at the end of the tail carries receptor-binding proteins, such as a central tail spike and tail fibres (yellow) of various lengths. Depending on tail length, a phage measures $25-200 \mathrm{~nm}$ from head to tail, thus sized between a large protein $(10 \mathrm{~nm})$ and small bacterium $(2,000 \mathrm{~nm})$. Chemical antibiotics are in the range of $1 \mathrm{~nm}$, thus $\times 1,000$ smaller than a bacteriophage. Artefact provided by African Creative, Cape Town, South Africa (africancreative.co.za).

guise (online suppl. Fig. S2) [10]. A detailed overview published in 2001 covering the history of phage therapy in Eastern Europe since its inception paints a picture of mixed success [15]. Phage preparations contained uncertain quantities of phage and sometimes bacterial debris from the manufacturing process [15]. On a positive note, phage treatments have been exceedingly safe apart from a few minor adverse events believed due to endotoxins either present in the product or released from bacteria lysed in vivo [15].

\section{Phage Biology}

Bacteriophages are viruses that infect bacteria. Phages represent the most abundant biological entities and can be found in every natural environment, including the human body. The number of phages on earth has been estimated to be $10^{31}$ particles. An estimated $10^{23}$ phages attack a bacterium in every second of the day [16]. Although phages have many shapes and sizes, and different types of genetic material, most phages in the environment are double-stranded DNA-tailed phages that constitute the Caudovirales (Fig. 1).

Phages have enormous genetic diversity; yet, they are extremely selective regarding the bacteria they can attack, and some phages only infect a small subset of strains (or clinical isolates) of any bacterial species. Genes are tightly packed in phage genomes, and it is typically simple to identify those involved in virion (i.e., particle) structure and assembly, lysis, and DNA metabolism. However, these may represent fewer than half the genes in any phage genome, and a majority of phage genes are of unknown function. The substantial genetic novelty and overall diversity of phages reflect the long (perhaps 3 billion years) evolution of a vast and highly dynamic viral population, in which there is strong selection pressure on bacteria to survive infection, and necessary co-evolution of the phages. Their enormous abundance and diversity make phages an unlimited arsenal for antibacterial weaponry against all human pathogens [17].

Most phages can be broadly grouped as being lytic or temperate (Fig. 2). Lytic phages form clear plaques on bacterial lawns, in contrast to the turbid plaques of temperate phages, which indicate incomplete killing and contain surviving, lysogenic bacterial cells. A typical lytic phage attack starts with binding to a specific surface receptor and injecting DNA into the bacterium, followed by early gene expression, DNA replication, late gene expression, particle assembly, lysis, and release of the progeny phages. A full lytic cycle typically yields 100-200 new particles and is complete in about the same time as the doubling time of their bacterial host. Temperate phages can also go through a full lytic cycle upon infection of a bacterial cell or can follow an alternative pathway (lysogeny) in which the genes needed for lytic growth are switched off, and the phage genome is established as a steadily maintained "prophage." The resulting lysogenic bacteria or "lysogens" thus, carry a prophage, which is typically either integrated site-specifically into the bacterial chromosome or replicates outside the nucleus in a plasmid-like state. Temperate phages are extremely common, and most sequenced bacterial genomes carry one or more integrated prophages $[18,19]$.

The rise of modern biotechnology from the turn of the century has revived interest in phage-based applications. With little fanfare, bacteriophages have advanced modern biotechnology into our daily lives on many fronts [20]. Several approved phage products prevent contamination of consumer goods, such as meat, fish, fruit, vegetables, and dairy products with pathogenic species such as Listeria monocytogenes, Salmonella enterica, Shigella, and Escherichia coli. Sprayed phage solutions are approved to protect growing plants and animals from bacterial disease. Phage-based biocides can penetrate biofilms to treat and protect surfaces from contamination or bac- 


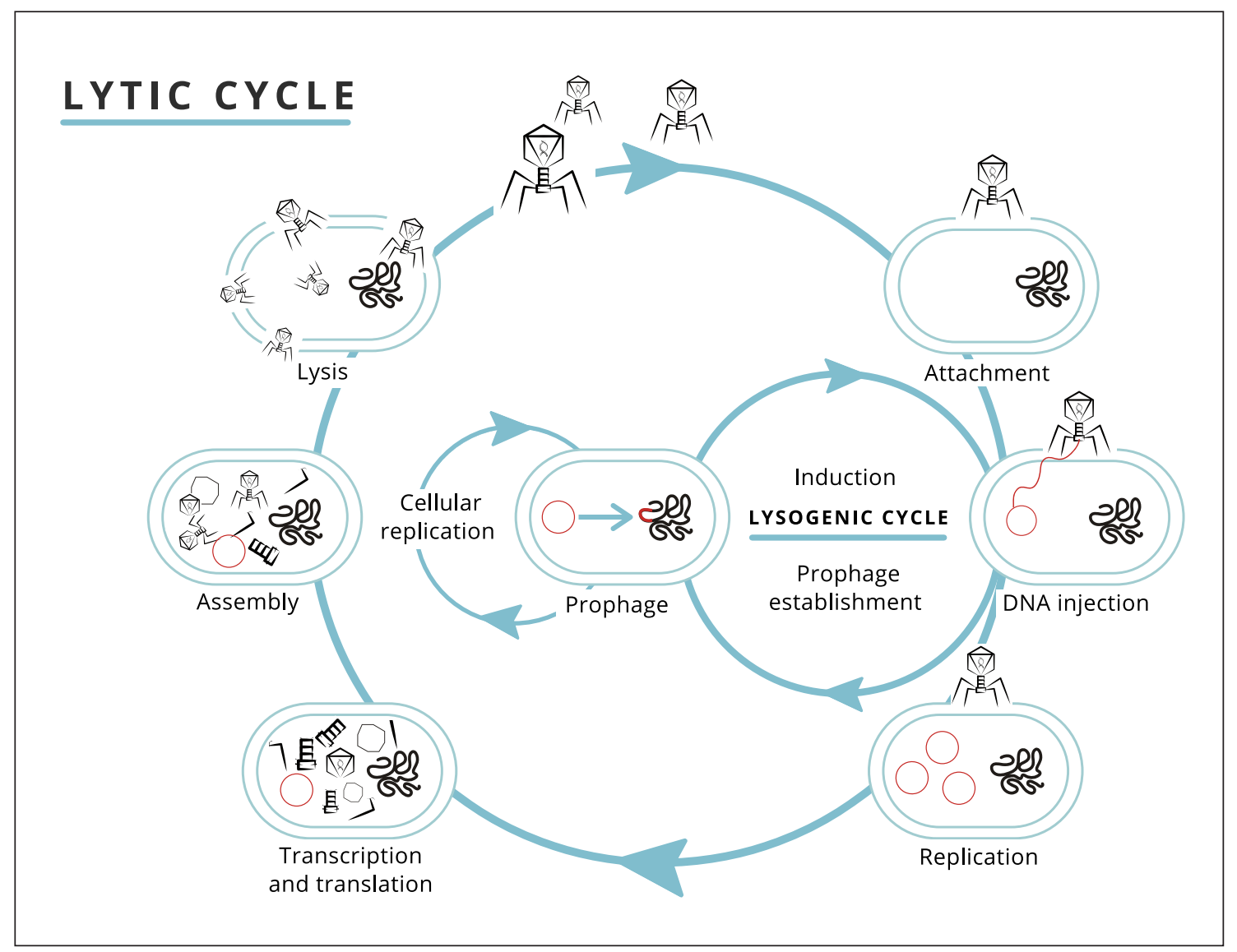

Fig. 2. Phage-induced lytic or lysogenic bacterial life cycles. Phages can be lytic, killing bacteria upon infection, or temperate, inducing lysogenic bacteria. To infect a host bacterium a phage needs to meet a target organism close enough to interact with receptors on the host cell, attach, and inject its genome. Lytic phages will immediately replicate inside the infected cell and lyse it leading to cell death. Temperate phages can form lysogens by preserving their DNA either in a free, plasmid-like state or integrate it into the bacterial chromosome and replicate along with the lysogenic bacterium until a lytic cycle is triggered.

teria-mediated corrosion. Biotechnological applications in development utilize phages as gene delivery vehicles, vaccine antigen carriers, biosensors, or as a toolbox for biological nanomaterials [20]. Importantly, phages are ideal for studying the principles of evolution and ecology and make excellent substrates for teaching and training emerging scientists [21,22].

\section{Bacteriophage Treatments}

A good example of early phage treatment success is a 1946 report in JAMA. Fifty-six patients with typhoid fever were treated with "type-specific phage" that is, phages grown on the patients' own isolates. All received phage intravenously once. Thereafter, all but 3 had negative blood cultures within 24 hours, became afebrile and normalized clinically [23]. The image series (Fig. 3) shows the case charts of a 9-year-old boy with a 3-week history of abdominal symptoms, progressive lethargy, and weakness, requiring transfusion, who improved dramatically with phage treatment and was subsequently discharged cured.

A modern example of the potential of phage therapy is the successful treatment of 10 dogs with chronic otitis caused by $P$. aeruginosa. A single external application of a cocktail of 6 phages that had been propagated on human $P$. aeruginosa isolates improved all dogs' ears without apparent toxicity [24]. The same group promptly followed up with a controlled trial in 24 humans with chronic, antibiotic-resistant otitis that was treated either conservatively or with the same external phage cocktail. Significant clinical improvements and reduced pseudomonal bacterial counts were observed up to 42 days after appli- 


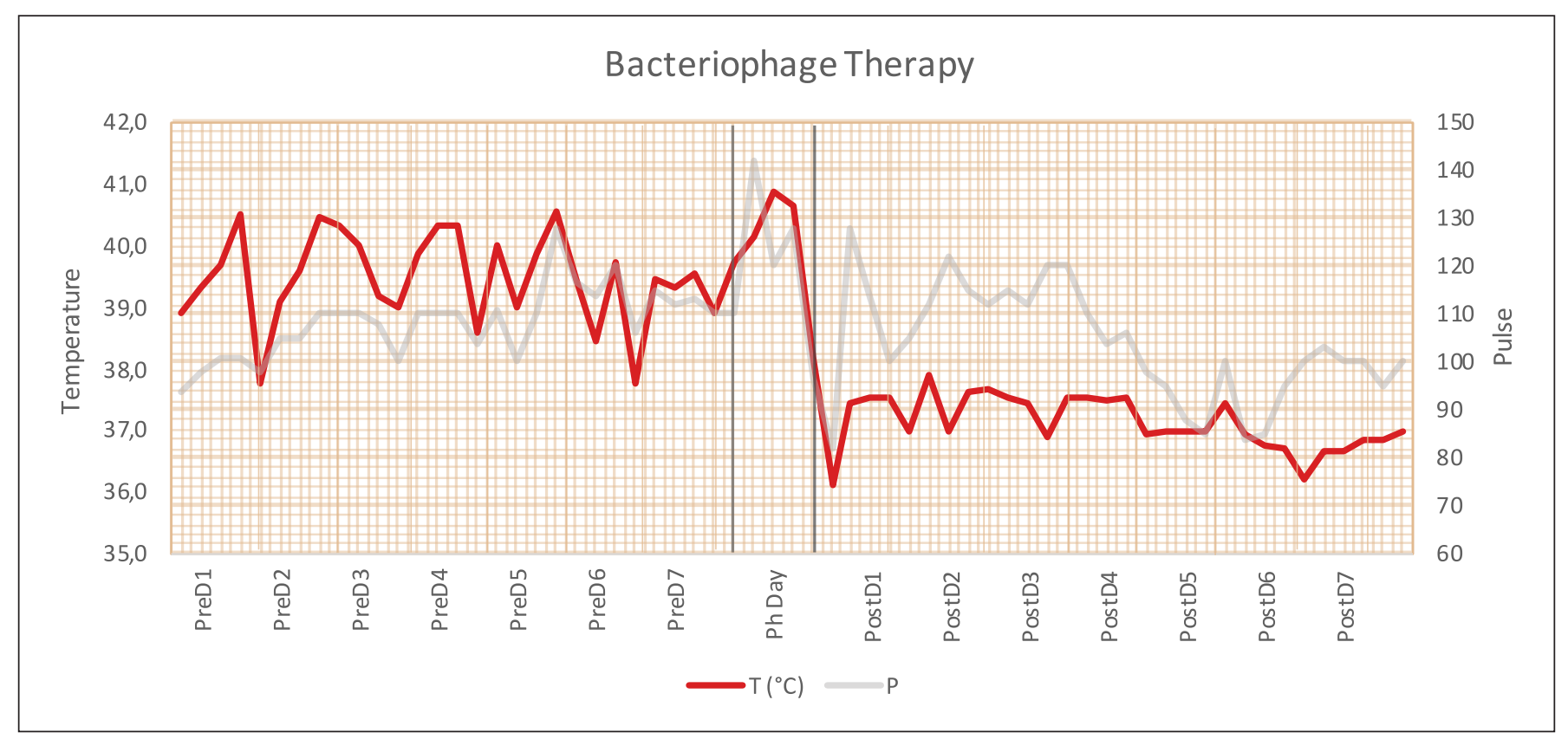

Fig. 3. Typhoid fever undergoing phage treatment. Hospital chart during a single intravenous phage treatment for typhoid fever. Temperature and pulse are charted in 6-h intervals. A caption from the medical notes reads: "Twenty-four hours after phage the most notable improvement was the remarkable change in the disposition and attitude of the child. He was interested in his surroundings for the first time since entry. Cultures of blood, stool, and urine remained negative. The patient was discharged as completely recovered." Redrawn from reference [23], published 1946.

cation, without treatment-related adverse events [25]. Sadly, the product could not overcome the regulatory obstacles to enter phase 3 trials and has not been brought to market (personal communication).

A prominent contemporary case report is that of a 68 -year-old diabetic patient with necrotizing pancreatitis complicated by a multi-drug resistant $A$. baumannii infection (online suppl. Fig. S3). Multiple antibiotic courses and percutaneous drainage of a pancreatic pseudocyst had failed. The situation was desperate when a cocktail of phages selected from phage banks and grown on an isolate from the patient was administered intravenously and percutaneously into the abscess cavities. This was associated with clinical improvement, clearance of the infection, and return to health. Despite the patient's critical condition, there were no discernible adverse clinical events [26]. The story was very carefully documented and later published as a book which praised the phage cocktail as "the perfect predator, that can kill even the most lethal bacteria." Successful and safe treatment of multidrug-resistant or persistent bacterial infections with phages was also reported in pre- and post-transplant patients, infections involving bones and implants, as well as persistent organ infections caused by Staphylococcus, Pseudomonas, Burkholderia, and other multi-drug resistant strains, further supporting progress using this approach [27-30].

\section{Mycobacteriophages}

\section{Discovery and Uses}

A virus that infects fast-growing, non-pathogenic mycobacterial hosts was first isolated in 1947 from soil [31]. By the time phages that infect slow-growing human pathogens, such as $M$. tuberculosis were discovered, efficacious anti-tuberculosis agents had already emerged and mycobacteriophages were relegated to phage typing [32, 33]. From the 1960s until the early 1980s, they were useful tools to identify subtypes of $M$. tuberculosis [34, 35]. These typing studies enabled observations on the virulence of different phage subtypes of M. tuberculosis as well as noting differences based on the patients' countries of origin. This was soon made obsolete with the development of faster and more sophisticated molecular typing techniques [36-38]; subsequently most of these phages have been lost and remain genetically uncharacterized. 


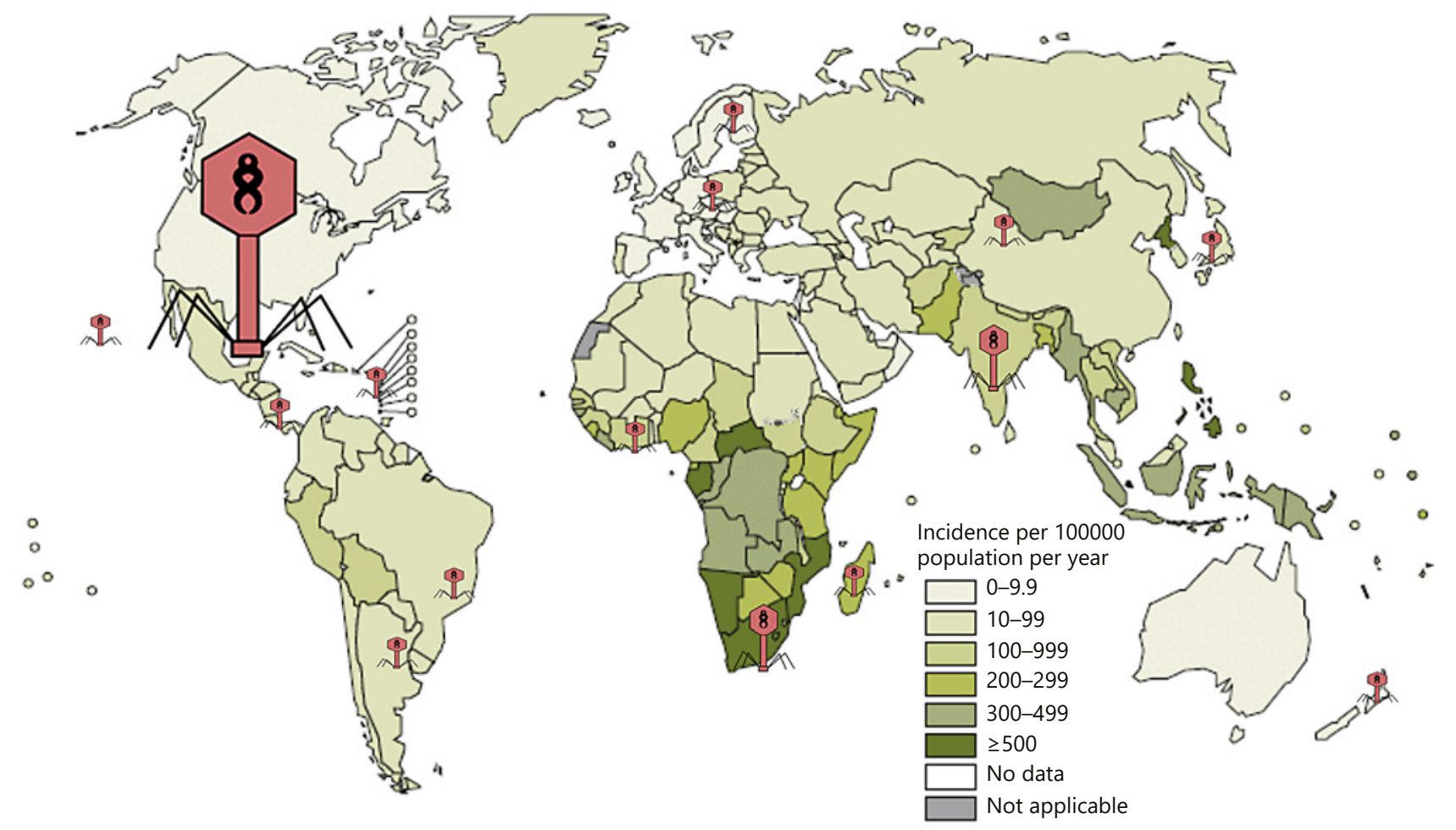

Fig. 4. Global mycobacteriophage isolation locations in the SEAPHAGES program. Global tuberculosis incidence and locations of mycobacteriophages discovered that have potential to infect $M$. tuberculosis (clusters A, G, K, see Fig. 5) are shown. The key to the colours for TB incidence is on the map. Phage numbers are represented in 4 sizes representing countries with $>100$ phages (XL, such as the USA), between 11 and 100 phages (L, none), between

\section{Phage Hunters of the New Age}

Since the turn of the millennium, the discovery and genomic characterization of mycobacteriophages has been the focus of integrated research and education programs, resulting in isolation of more than 10,000 mycobacteriophages from environmental samples using a single host strain, Mycobacterium smegmatis $\mathrm{mc}^{2} 155$ (Fig. 4) $[22,40,41]$. Over 2,000 of these have been sequenced and annotated, and sorted into 38 genome "types" (i.e., clusters, subclusters, singletons), 9 of which have only a single member (i.e., "singletons"), suggesting there are many different phages of $M$. smegmatis $\mathrm{mc}^{2} 155$ still to be discovered [42]. Comparative genomic analysis shows that the mycobacteriophages are architecturally mosaic and built from smaller units (often single genes) assembled in different combinations and present in different genomic
3 and 10 phages (M, such as South Africa or India) or 1 to 2 phages ( $\mathrm{S}$, all others). Phages that can potentially infect $M$. tuberculosis have mainly been hunted and found in areas where TB prevalence is low. A large reservoir of potentially useful mycobacteriophages is probably still untapped in areas with high tuberculosis incidence. Maps from https://seaphages.org and WHO [39]. TB, tuberculosis contexts $[43,44]$. A few of the phages discovered have an expanded host range including non-virulent members of the M. tuberculosis complex or multiple lineages of human pathogenic M. tuberculosis or Mycobacterium africanum $[21,45,46]$.

\section{Mycobacteriophages and Mycobacterium Tuberculosis}

\section{M. tuberculosis as a Target for Mycobacteriophages}

$M$. tuberculosis has evolved recently as a human pathogen, with key events occurring only in the past few thousand years $[2,3] . M$. tuberculosis is now adapted to an intracellular milieu where it survives long term within a latently infected human host, only occasionally dispatch- 
ing extracellular organisms into aerosols coughed out by patients with active disease to ensure transmission [1]. The concept of immunosubversion postulates that pathogen survival is ensured by interaction with the immune system that benefits the pathogen [1]. Most pathogens attempt to escape host immunity by mutation of their antigens which drive genetic diversity. In contrast, M. tuberculosis' strategy of immunosubversion encourages conservation of antigens and leads to low sequence diversity [47]. Only 9 lineages that are causative of human tuberculosis have been described [48]. Lineages L1, L2, L3, L4, and L7 are M. tuberculosis sensu-strictu; L5 and L6 are $M$. africanum and only occur in West Africa. Linages L8 and L9 are very rare $[1,48]$. This limited strain variation is a positive indicator for considering phage therapeutics, as it enhances the prospects that phages capable of infecting any one strain should be able to infect most others.

\section{Phages Targeting M. tuberculosis}

There are some key requirements for an effective phage cocktail for tuberculosis treatment. Candidate phages must infect both M. tuberculosis and M. smegmatis so that the large quantities needed for clinical use can be produced safely and efficiently on the fast-growing, non-pathogenic $M$. smegmatis strain outside stringent biosafety environments. Lytic phages are preferable because very few bacterial cells will survive the infection, and the phage self-eliminates when no more bacterial hosts are accessible. Temperate phages can form lysogens which survive happily and grow well, but in this process can transfer genes to bacteria potentially leading to increased host virulence or antibiotic resistance. Temperate phages can be genetically manipulated to negate their ability to switch off the lytic genes or chromosomally integrate, and thus become suitable for therapeutic use. Such knowledge and technical ability is a major advance over how phage treatments were designed before the advent of modern biotechnology. It is also important to assemble phage cocktails that will not only infect and kill a wide range of clinical isolates, but are also diverse enough to minimize prospects for phage resistant derivatives to emerge [46].

\section{A Candidate 5-Phage Cocktail for Tuberculosis \\ Treatment}

Phage preparations for compassionate use in AMR cases are typically personalized by using the patient's own pathogenic strain to identify therapeutically useful phages and selecting the most diverse phage-mix efficient in killing that specific bacterial strain. Such highly individu- alized treatment is not practical for tuberculosis because selecting effective phages on slow-growing $M$. tuberculosis would take too long and be overly costly. Owing to the low genetic diversity of $M$. tuberculosis, such individualized treatment is fortunately not necessary. The expectation that a mycobacteriophage effective on 1 strain will likely cover most others was exploited by Guerrero-Bustamente et al. [46] to assemble a phage cocktail with optimal therapeutic potential for tuberculosis. Phages were sourced from a subset of sequenced M. smegmatis phages that infect other bacterial species, including $M$. tuberculosis H37Rv. Typically, these phages will correspond to particular genomic types from which mutants with an expanded host-range can be isolated that infect different mycobacterial hosts (Fig. 5). Using a combination of genome engineering and bacteriophage genetics, a 5-phage cocktail was assembled with enough diversity to minimize the emergence of phage resistance and cross-resistance to multiple phages [46]. Each phage has demonstrated killing activity on a set of $M$. tuberculosis strains representing all major lineages of human-adapted strains [46]. All phages in the cocktail are fully characterized and are naturally lytic or lytic derivatives of temperate phages. All function without antagonizing antibiotic efficacy and have been shown to infect both isoniazid-resistant and -sensitive strains [46].

\section{Mycobacteriophage Treatment}

\section{Pre-Clinical Experience with Mycobacteriophage \\ Treatments}

Mycobacteriophages as potential therapeutic options for tuberculosis have been investigated in the past in vitro [45] and in guinea pigs infected with M. tuberculosis [4951], but not in humans. These early studies were reported as promising but failed to effect a cure, which was reasoned to be due to the use of temperate phages not causing cell lysis, failure of phages to enter tuberculous granulomas, or neutralizing host immune responses to large numbers of phages applied repetitively [52].

The concept of prophylactic use of mycobacteriophages for protection against $M$. tuberculosis infection has been suggested at least since 2012 [17, 53, 54]. Carrigy et al. $[55,56]$ first investigated the most suitable nebulizer type for phage inhalation and then exposed mice to an inhaled aerosol of mycobacteriophage D29, followed within $30 \mathrm{~min}$ by $M$. tuberculosis $\mathrm{H} 37 \mathrm{Rv}$ aerosol to the lungs. A prophylactic effect was observed with bacteriophage aerosol pre-treatment significantly decreasing $M$. 


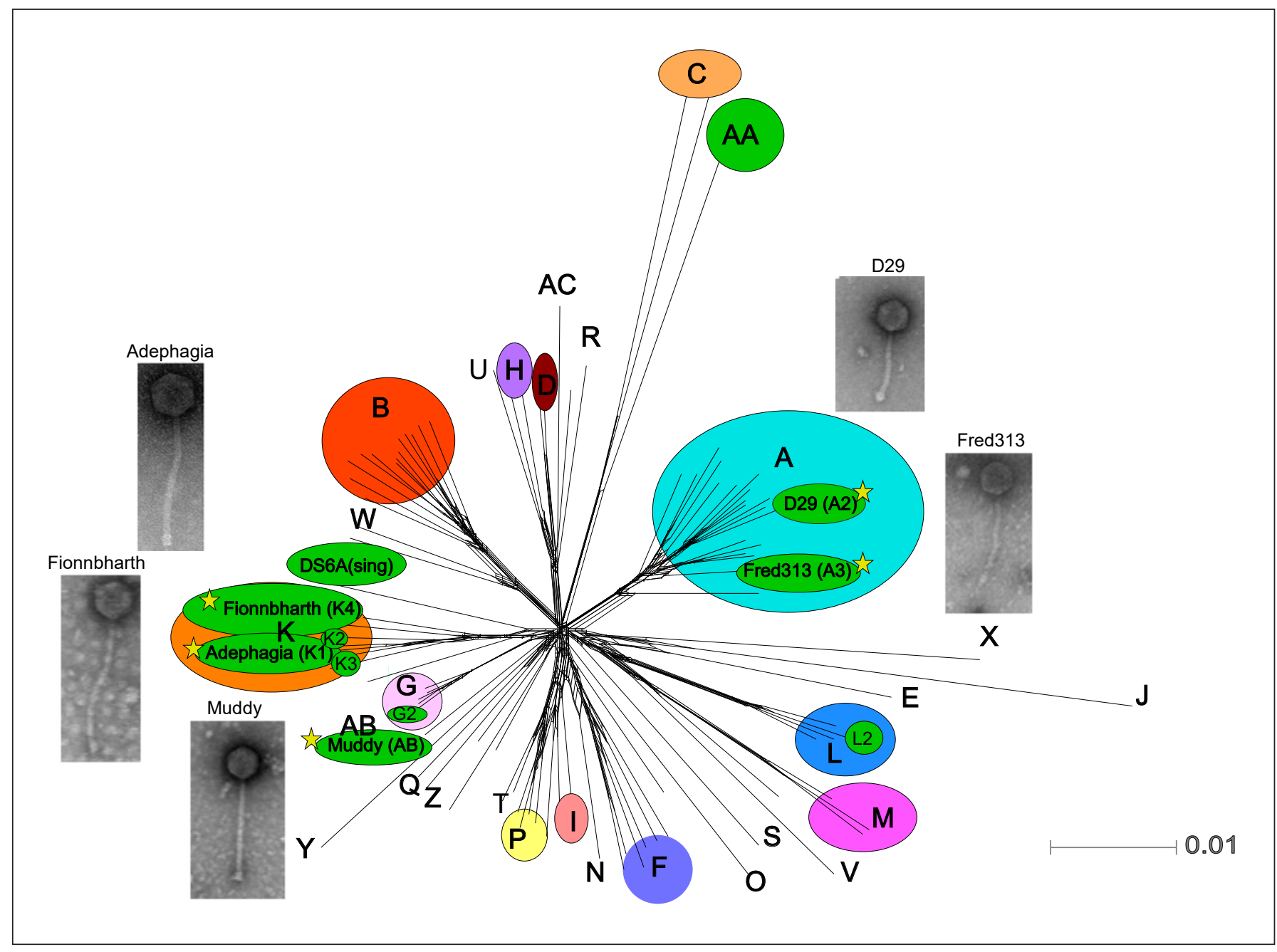

Fig. 5. Mycobacteriophage diversity. Sequenced mycobacteriophages are compared based on gene content similarity and the relationships are displayed using Splitstree (splitstree.org). Phages that correlate closely with their gene content are divided into clusters (A, B, C, ... displayed in coloured circles) and subclusters within (A1, A2, A3...). Letters without circles represent clusters that, to date, have not been divided into subclusters. Lines with no letter labels represent singleton genomes that have no close rela- tives. Subclusters or individual phages known to infect $M$. tuberculosis are in green ovals. Individual names such as Fionnbharth, Muddy or Adephagia are chosen by the discoverer of the phage (within SEA phages naming rules). The 5 phages proposed for the tuberculocidal cocktail infect both $M$. smegmatis and $M$. tuberculosis complex efficiently and have a star beside the phage name. Micrographs of these phages are shown. All these phages are of siphoviridae morphology possessing a long, non-contractile tail. tuberculosis burden in mouse lungs 24 hours and 3 weeks post-challenge. This suggests that a single dose of nebulized mycobacteriophage aerosol could protect from infection with M. tuberculosis following exposure which naturally occurs with much fewer bacteria than used in this experiment [56].

\section{Clinical Experience with Mycobacteriophages}

Dedrick et al. [57] reported the first and so far only therapeutic use of mycobacteriophages for a human in- fection. A 15-year-old patient with cystic fibrosis and disseminated, antibiotic-resistant Mycobacterium abscessus infection following bilateral lung transplantation was treated with a 3-phage cocktail. Some naturally temperate phages were genetically modified to ensure lytic activity. Intravenous phage treatment was well tolerated and associated with sterilization of bacterial cultures and objective clinical improvement, including wound closure, substantial resolution of infected skin nodules, and dramatic recovery of dynamic lung function parameters (Fig. 6). 
There were no reported adverse reactions to intravenous phage administration [57]. A number of additional cases have since been treated with mycobacteriophages targeting $M$. abscessus $[27,58]$.

\section{Dosage and Delivery}

To take advantage of self-replication at the site of disease, a unique property of phages, sufficient phage numbers must encounter enough bacteria to start a self-augmenting reaction $[59,60]$. Paradoxically, higher phage numbers might be required in milder disease cases in order to provide the same chance of phage-target encounters when fewer target pathogens are present. Phage therapy alone might not be effective in situations where most remaining target cells reside intracellularly or inside granulomas. In humans with tuberculosis, a combination of intravenous application and nebulization might be needed to maximize the chance of a critical number of phages hitting extracellular target bacteria and starting a killing reaction. Phage inhalation to disease site is an attractive and safe option, and has been explored in clinical trials in cystic fibrosis with chronic $P$. aeruginosa infection $[61,62]$. Phages can also be prepared as a dry powder for easy administration by handheld inhalers [63].

\section{Phage Clearance and Interaction with Antibiotics}

Following iv administration, phages are quickly removed from circulation by the phagocytic system [64, 65]. In 2 recent cases, phages were administered as a single dose intravenously and remained detectable no longer than $50 \mathrm{~min}$ and $120 \mathrm{~min}$, respectively $[26,66]$. At the site of action, phages are self-dosing by initially augmenting their numbers and self-eliminating once all pathogens are killed; however, it has recently been shown that phages use quorum sensing with small peptides to communicate and slow down killing once the reservoir of new hosts to infect becomes critically low [67]. Repeated dosing, alternative phages or co-medication with antibiotics might be needed to eradicate an infection.

KatG-mediated isoniazid resistance does not influence bacterial susceptibility to phage lysis in the proposed cocktail [46]. Additionally, a combination of phage Fionnbharth (a member of the phages proposed for tuberculosis treatment, Fig. 5) with isoniazid or rifampicin did not diminish the killing observed with antibiotics or phages alone [46]. That said, antibiotics that disrupt bacterial protein synthesis can be detrimental to phage propagation [68]. Conversely, it has been shown that phageinfected Burkholderia cenocepacia produced higher phage counts in the presence of sub-inhibitory concen-

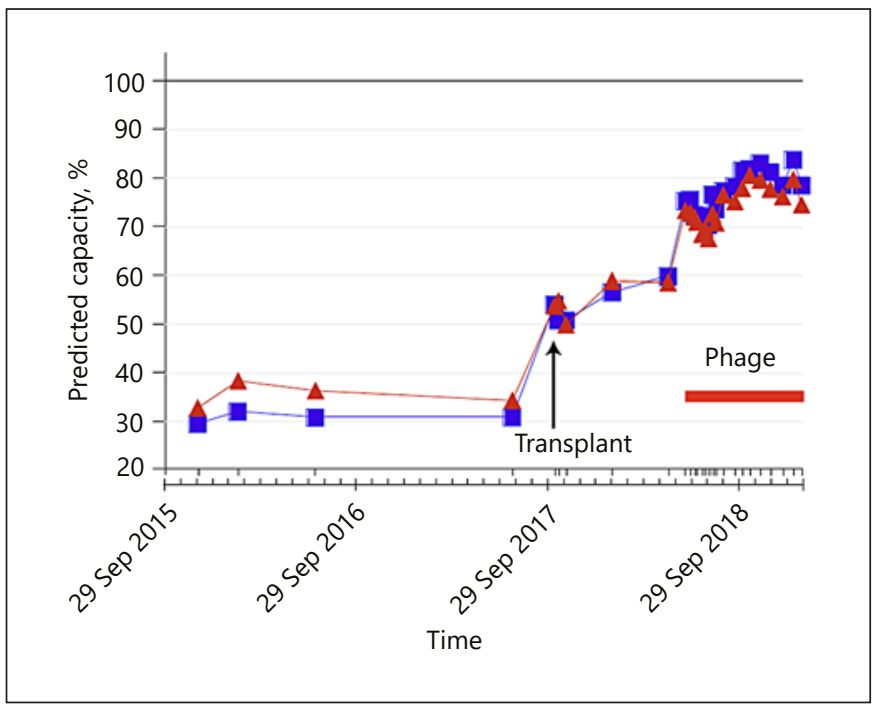

Fig. 6. Post-transplant spirometry before and after phage treatment. Patient status before and after phage treatment from reference [57], with permission. Lung function is shown as per cent predicted FEV1 (blue) and FVC (red). FEV1, forced expiratory volume in $1 \mathrm{~s}$; FVC, forced vital capacity.

trations of some antibiotics [69], and multi-drug resis$\operatorname{tant} A$. baumanii bacteria reverted to being antibioticsusceptible once again following phage treatment [26]. Considering that many tuberculosis patients with advanced drug resistance are on reserve drugs, a phage product for TB should be scrutinized for potential interactions with such agents to ensure that they can be used together, and that antibiotic resistance is not associated with loss of phage infectivity.

\section{Phage Resistance}

Owing to the constant struggle of bacteria to rid themselves of phage attacks, it is not surprising that multiple mechanisms of phage resistance exist and can arise with phage treatment [5]. Spontaneous chromosomal mutations that make it impossible for the phage to attach or enter the bacterial cells are the most common. Furthermore, the injection of phage DNA can be blocked, or the DNA destroyed by viral defence mechanisms such as CRISPR-Cas systems. A plethora of intracellular proteins can cause abortion of phage infection or multiplication [70].

Few phage resistance mechanisms have been described for Mycobacteria, of which those involving M. smegmatis, M. tuberculosis, and the phages in the treatment cocktail (Fig. 5) are of interest here. Increasing expression of the mpr locus - part of an ABC transporter operon - in $M$. 
smegmatis was shown to cause resistance to phages D29 and L5 [71, 72]. Resistance to phage I3 in M. smegmatis results from mutations affecting glycopeptidolipids synthesis, which presumably act as the surface receptor for the phage [73]. In M. tuberculosis, a mutation upstream of locus Rv1043C was shown to result in resistance to the distantly related cluster K phages Fionnbharth and Adephagia; additionally, a nonsense mutation in locus Rv1712 (cmk) results in resistance to phage Adephagia [46]. The resistance mechanisms are unclear. $M$. tuberculosis has a CRISPR array with variable spacers (as used in spoligotyping), suggesting that these were used to defend against phage attack in its past. We also note that $M$. tuberculosis has a large number of toxin-antitoxin systems, which are also implicated in viral defence [74].

Diverse and lytic phages engineered from M. smegmatis, as proposed by Guerrero-Bustamente [46], are unlikely to encounter spontaneous resistance. This would have to arise sporadically by spontaneous mutations which are known to occur at a very low rate in $M$. tuberculosis. Resistance would thus arise no faster than to antibiotics and only against a single phage at a time. By targeting a range of highly conserved surface receptors that are essential for bacterial survival, and by constantly monitoring resistance arising and updating the phage cocktail, such treatments should remain effective for a long time [10]. Importantly, evolution of broad anti-bacteriophage mechanisms, as seen in response to conventional antibiotic therapy, are unlikely to arise because drug-resistant $M$. tuberculosis strains accumulate individual target gene mutations rather than broad defence mechanisms such as efflux pumps. This makes it relatively unlikely that diverse drug-resistant strains will have markedly different phage infection profiles [46]. There is also no evidence that $M$. tuberculosis acquires phage resistance through an adaptive CRISPR-mediated immune response.

\section{Safety of Phage Treatments}

In the USA, the use of phages is approved for the decontamination of food, plant-based and livestock products, or surfaces [10]. In this context, the U.S. Environmental Protection Agency (EPA) has stated that the literature demonstrates that bacteriophages are ubiquitous naturally occurring organisms, that humans are exposed daily to these organisms without adverse effects, and that phages are non-toxic and non-pathogenic to humans and animals [75].

Phages are host- and receptor-specific and therefore only capable of infecting a narrow spectrum of bacteria and not human cells. This high specificity notably results in minimal harm to host microbiomes, such as gut flora [76]. Lytic phage therapy is regularly utilized in Eastern Europe, where some phage cocktails are available without prescription [77]. Studies and case reports have consistently demonstrated that phages, when properly purified and prepared are not inherently harmful to humans [78]. Luong et al. [65] provide a comprehensive summary of adverse events reported in 56 published clinical trials and case reports from 2005 to 2020 . Adverse events were reported in only 12 reports (21\%) and were mild and transient. A single event of suspected anaphylaxis was later explained by exacerbation of pre-existing heart failure, and phage treatment was resumed without incident $[15$, 79]. Considering that compassionate phage treatments are often used in desperate situations and correspondingly frail patients, the absence of concerning events is reassuring. Some phage proteins seem able to elicit immune responses when high doses of phages are given over a long time [80]. In humans, neutralizing anti-phage antibodies have been found in people who did and did not undergo phage treatments. In at least one case, such antibodies have been postulated to limit the success of experimental phage therapy $[58,81]$.

\section{Legal and Regulatory Framework}

Bacteriophage therapy, as used in some parts of Europe, is not formally authorized as a medicinal product. It is obvious that increasing investment into the development of phage-based treatments critically depends on supportive regulations regarding marketing authorizations and protection of intellectual property. Natural phages are a natural resource and cannot be patented as such, but genetic modifications, a manufacturing method or the production process of a phage mixture could receive such protection. Regulations for the clinical evaluation of the safety and efficacy of bacteriophage therapies are not currently in place at the US Federal Drug Administration (FDA) or the European Medicines Agency (EMA) [82]. However, both agencies have recognized the importance of emerging phage products for human use and are in the process of developing regulatory frameworks through consultation with developers and workshops $[83,84]$. Developers are urged to engage in early dialogue by applying for guidance. Clinical trials to increase the body of evidence about phage treatments are explicitly encouraged [85].

The FDA has approved numerous phage therapies as experimental treatments through the Center for Innovative Phage Applications and Therapeutics (iPATH) established in 2018 in San Diego, CA, USA [27]. Aslam et
Diacon/Guerrero-Bustamante/ Rosenkranz/Rubio Pomar/Vanker/Hatfull 
Table 1. Suitability of pulmonary tuberculosis for mycobacteriophage therapy

Is there unmet need?

\begin{tabular}{lll}
\hline Confirmed bacterial pathology & Pro & M. tuberculosis \\
\hline Need is sufficient to support planned development & Pro & Global significance \\
work & & Millions of cases yearly \\
& Rising resistance rates \\
& Few new antibiotics \\
\cline { 2 - 3 } & Con $\quad$ Not attractive for profit-oriented investment at this time
\end{tabular}

Is the disease suitable for phage therapy?

Single or limited number of bacterial species $\quad$ Pro Low strain diversity of MTB facilitates a "one cocktail for all" approach responsible for pathology

\begin{tabular}{lll}
\hline Quantitative assay for target bacteria & Pro & Sputum counts and culture conversion as done in antibiotic studies \\
\hline Suitable model systems available & Pro & Hollow fibre and animal models \\
\cline { 2 - 3 } & Con & Models imperfect for human disease \\
\hline Accessible site of infection & Pro & Per inhalation or intravenously \\
\hline Bacterial density to support amplification & Pro & $\begin{array}{l}\text { Extracellular MTB implicated in pulmonary TB and expelled sputum and } \\
\text { as droplets }\end{array}$ \\
\cline { 2 - 3 } & Con & Intracellular nature of MTB and granuloma formation limit phage access \\
\hline Patient group suitable for trials & Pro & In high prevalence areas \\
\hline
\end{tabular}

Are suitable bacteriophages available?

\begin{tabular}{ll}
\hline Mycobacteriophages & Pro $\quad$ Effective 5-phage cocktail [91] \\
& Obligately lytic \\
& No transduction potential \\
& Genetically diverse \\
& Active against all lineages of MTB \\
& Beneficial resistance profiles
\end{tabular}

\begin{tabular}{lll}
\hline High levels of growth in suitable bacterial hosts & Pro & Dual infection of fast-growing M. smegmatis and MTB \\
\hline Stability and purity of product & Pro & Manufacture to GMP standard as explored in other therapeutic areas
\end{tabular}

MTB, M. tuberculosis. Adapted from Harper [90].

al. [27] recently reported the first series of compassionate phage treatments for which approval was granted through the FDA's "Emergency Investigational New Drug" scheme on a case-by-case basis. The application required evidence of clinical need, proof of in vitro bacterial susceptibility to the phages, genetic characterization of the phages with particular focus on plasmids encoding for resistance mechanisms, lack of lysogenic activity, sterility of the final product, and minimal endotoxin concentration [27].

\section{Investment and Funding}

At least 10 companies were known to be developing new phage treatments in 2019 [86]. Target areas include relapsing bone infection with or without surgical implants, diabetic foot ulcers infected by $S$. aureus, as well as $P$. aeruginosa infections in chronic lung diseases and cystic fibrosis [87-89]. A common feature to these conditions is advanced AMR and difficult access to the site of infection due to low perfusion, foreign material, scar tissue, or bacterial sequestration in mucus. While such treatments might meet with commercial success at some point, efforts aiming to progress the potential of mycobacteriophage to combat tuberculosis are of global interest and therefore need joint efforts from public and private partners potentially distributed all over the world. Similarly, it would require the joint will and capacity of various funding programs combining efforts to secure sufficient funding for 
its progression and sufficient stakeholder support to efficiently plan future steps. A mycobacteriophage treatment would reinforce the AMR fight, challenging one of the deadliest bacteria, potentially reducing either the number of drugs and/or the treatment time required, which are both effective strategies to reduce resistance. It is important to set a sustainable approach beyond a proof-of-concept study, with regulatory approval and escalation to pharmaceutical quality industrial production manufacturing in mind, while also taking into account the potential impact, in drug development and TB, as well as potential translation to other diseases.

\section{Is There a Place for Mycobacteriophages in Modern Medicine?}

The increase in AMR has renewed interest in bacteriophages as an alternative to antibiotics. M. tuberculosis is genetically not diverse, and not currently under regular phage attack. Compared to its environmental ancestors the genome of human-adapted M. tuberculosis is considerably smaller [1]. It can be speculated that previously active phage defence mechanisms have been made redundant by intracellular life. We now know that the "direct repeat" regions on the $M$. tuberculosis genome that have been used for decades to genotype M. tuberculosis represent a defunct CRISPR system to defend against phages. Contemporary M. tuberculosis might be ill prepared to defend against phage attack, particularly when confronted with diverse phages that have been genetically engineered to be lytic and protect each other from resistance.

Criteria for selecting suitable infectious diseases for phage therapy as recently proposed by Harper [90] are shown adapted in Table 1. To explore the potential of phages in TB, the extracellular bacteria found in contagious droplets and expectorated sputum from active $\mathrm{TB}$ patients are an attractive target for proof-of-concept trials. These trials should include pharmacokinetic/dynamic assessments to evaluate the optimal concentration, dosing interval, and duration of treatment, as well as assessments for a possible host immune response or phage resistance [27]. A single application of a phage product to eradicate latent TB would be an interesting long-range target, but this would likely depend on the location of dormant organisms in the host and whether phages are able to circulate to and penetrate that milieu. With a lytic phage cocktail becoming available, the next steps are production to an acceptable standard of purity for clinical trials that can be initiated following consultation with regulatory and ethics bodies. In carefully conducted clinical trials the optimal dose, frequency, and route of administration must be investigated, as well as interactions with currently available anti-tuberculosis agents. In practice, patients with highly drug-resistant TB have the greatest need for alternative treatment options and should be the first target group to receive phage treatment for clinical benefit, thereby responding to the global call to combat AMR.

Most M. tuberculosis found in sputum are extracellular and the effect of phage treatment should be measurable by a drop in the viable mycobacterial sputum load. Penetration into and activity within granulomas and phagocytes, where some mycobacteria are expected to reside, will be harder to achieve $[15,92]$. Phages have been shown to penetrate biofilms well, and they can kill persister-type bacteria, though this has not been shown with $M$. tuberculosis [92]. An intriguing suggestion for addressing the issue of transportation of phages into granulomas and phagocytes is to use phage-infected non-pathogenic mycobacterial cells for the delivery to such locations [93]. Recent experience with novel mRNA vaccines for COVID-19 prevention has shown that small proteins can be successfully delivered to phagocytes by coating them in liposomes, which would also protect the phages from circulating antibodies $[10,94,95]$.

\section{Conclusion}

One can argue that releasing genomically altered yet ancient viral agents onto bacteria that have successfully defended themselves in a battle of co-evolution for eons, seems like trying the same thing over and over again hoping for a different outcome. However, the same could be said about antibiotics used centuries ago by pressing moulded bread against wounds. The vast majority of antibiotics in use today are derived from natural sources and were made into useful and broadly accessible therapeutics only by human manipulation. With modern sequencing techniques, we have now acquired the bioengineering tools necessary to harness what looks like an inexhaustible source of viral weaponry against bacteria that are poorly prepared for such an attack. It is clear that the supply of natural sources for antibiotics is nearing exhaustion, and inevitable that resistance rates to available antibiotics will keep rising. Bold investment, coordinated efforts, and forward thinking are needed to stay ahead. It might look futuristic to launch a swarm of aerosolized mycobacteriophages, attempting to land them on hostile
Diacon/Guerrero-Bustamante/ Rosenkranz/Rubio Pomar/Vanker/Hatfull 
M. tuberculosis that have taken residence in a human lung. Then again, this is not unlike launching swarms of humans into space to land them on Mars in an attempt to take residence there.

\section{Funding Sources}

This work had no external funding source.

\section{Author Contributions}

\section{Conflict of Interest Statement}

All authors contributed equally to this article.

None of the authors has a conflict of interest to declare.

\section{References}

1 Gagneux S. Ecology and evolution of Mycobacterium tuberculosis. Nat Rev Microbiol. 2018 Apr;16(4):202-13.

2 Hershkovitz I, Donoghue HD, Minnikin DE, Besra GS, Lee OY-C, Gernaey AM, et al. Detection and molecular characterization of 9,000-year-old Mycobacterium tuberculosis from a Neolithic settlement in the Eastern Mediterranean. In: Ahmed N, editor. PLoS One. 2008;3(10):e3426.

3 Sabin S, Herbig A, Vågene ÅJ, Ahlström T, Bozovic G, Arcini C, et al. A seventeenth-century Mycobacterium tuberculosis genome supports a Neolithic emergence of the Mycobacterium tuberculosis complex. Genome Biol. 2020 Dec;21(1):201.

4 Houben RMGJ, Dodd PJ. The global burden of latent tuberculosis infection: a re-estimation using mathematical modelling. In: Metcalfe JZ, editor. PLoS Med. 2016 Oct 25; 13(10):e1002152.

5 El Haddad L, Harb CP, Gebara MA, Stibich MA, Chemaly RF. A systematic and critical review of bacteriophage therapy against multidrug-resistant ESKAPE organisms in humans. Clin Infect Dis. 2019 Jun 18;69(1):16778.

6 Antimicrobial resistance [Internet]. [cited 2021 May 14]. Available from: https://www. who.int/news-room/fact-sheets/detail/antimicrobial-resistance.

7 Review on antimicrobial resistance. Tackling drug-resistant infections globally: final report and recommendations [Internet]. London, UK: Wellcome Trust and UK Government; May 2016 [cited 2021 Jun 6]. Available from: https://amr-review.org/Publications.html.

8 Medical Research Council. Streptomycin treatment of pulmonary tuberculosis: a medical research council investigation. Br Med J. 1948 Oct 30;2(4582):769-82.

9 Gillespie SH. Evolution of drug resistance in Mycobacterium tuberculosis: clinical and molecular perspective. Antimicrob Agents Chemother. 2002 Feb;46(2):267-74.

10 Allué-Guardia A, Saranathan R, Chan J, Torrelles JB. Mycobacteriophages as potential therapeutic agents against drug-resistant tuberculosis. Int J Mol Sci. 2021 Jan 13;22(2): 735.
11 Knight GM, McQuaid CF, Dodd PJ, Houben RMGJ. Global burden of latent multidrug-resistant tuberculosis: trends and estimates based on mathematical modelling. Lancet Infect Dis. 2019 Aug; 19(8):903-12.

12 Global tuberculosis report 2020 [Internet]. [cited 2021 May 14]. Available from: https:// www.who.int/publications-detail-redirect/9789240013131.

13 Dublanchet A, Bourne S. The epic of phage therapy. Can J Infect Dis Med Microbiol. 2007;18(1):15-8.

14 Ackermann H-W. Bacteriophage electron microscopy. In: Łobocka M, Szybalski WT, editors. Advances in virus research [Internet]. San diego, USA: Elsevier; 2012. p. 1-32 [cited 2021 May 14]. Available from: https:// linkinghub.elsevier.com/retrieve/pii/ B9780123946218000170.

15 Sulakvelidze A, Alavidze Z, Morris JG. Bacteriophage therapy. Antimicrob Agents Chemother. 2001 Mar;45(3):649-59.

16 Hatfull GF, Hendrix RW. Bacteriophages and their genomes. Curr Opin Virol. 2011 Oct; 1(4):298-303.

17 Hatfull GF. The secret lives of mycobacteriophages. In: Łobocka M, Szybalski WT, editors. Advances in virus research [Internet]. San diego, USA: Elsevier; 2012. p. 179-288 [cited 2021 Apr 3]. Available from: https:// linkinghub.elsevier.com/retrieve/pii/ B9780123946218000157.

18 Nobrega FL, Vlot M, de Jonge PA, Dreesens LL, Beaumont HJE, Lavigne R, et al. Targeting mechanisms of tailed bacteriophages. Nat Rev Microbiol. 2018 Dec;16(12):760-73.

19 Salmond GP, Fineran PC. A century of the phage: past, present and future. Nat Rev Microbiol. 2015 Dec;13(12):777-86.

20 Harada LK, Silva EC, Campos WF, Del Fiol FS, Vila M, Dąbrowska K, et al. Biotechnological applications of bacteriophages: state of the art. Microbiol Res. 2018 Jul;212-3:38-58.

21 Jacobs-Sera D, Marinelli LJ, Bowman C, Broussard GW, Guerrero Bustamante C, Boyle MM, et al. On the nature of mycobacteriophage diversity and host preference. Virology. 2012 Dec;434(2):187-201.

22 Hanauer DI, Graham MJ, SEA-PHAGES; Betancur L, Bobrownicki A, Cresawn SG, et al.
An inclusive Research Education Community (iREC): impact of the SEA-PHAGES program on research outcomes and student learning. Proc Natl Acad Sci U S A. 2017 Dec 19; 114(51):13531-6.

23 Knouf EG. Treatment of typhoid fever with type specific bacteriophage: preliminary report. J Am Med Assoc. 1946 Sep 21;132(3): 134.

24 Hawkins C, Harper D, Burch D, Anggård E, Soothill J. Topical treatment of Pseudomonas aeruginosa otitis of dogs with a bacteriophage mixture: a before/after clinical trial. Vet Microbiol. 2010 Dec;146(3-4):309-13.

25 Wright $\mathrm{A}$, Hawkins $\mathrm{CH}$, Anggård EE, Harper DR. A controlled clinical trial of a therapeutic bacteriophage preparation in chronic otitis due to antibiotic-resistant Pseudomonas aeruginosa; a preliminary report of efficacy. Clin Otolaryngol. 2009 Aug;34(4):349-57.

26 Schooley RT, Biswas B, Gill JJ, Hernandez-Morales A, Lancaster J, Lessor L, et al. Development and use of personalized bacteriophagebased therapeutic cocktails to treat a patient with a disseminated resistant Acinetobacter baumannii infection. Antimicrob Agents Chemother. 2017 Oct;61(10):e00954-17.

27 Aslam S, Lampley E, Wooten D, Karris M, Benson C, Strathdee S, et al. Lessons learned from the first 10 consecutive cases of intravenous bacteriophage therapy to treat multidrug-resistant bacterial infections at a single center in the United States. Open Forum Infect Dis. 2020 Sep 1;7(9):ofaa389.

28 Aslam S, Courtwright AM, Koval C, Lehman SM, Morales S, Furr CL, et al. Early clinical experience of bacteriophage therapy in 3 lung transplant recipients. Am J Transplant. 2019 Sep;19(9):2631-9.

29 Law N, Logan C, Yung G, Furr CL, Lehman SM, Morales S, et al. Successful adjunctive use of bacteriophage therapy for treatment of multidrug-resistant Pseudomonas aeruginosa infection in a cystic fibrosis patient. Infection. 2019 Aug;47(4):665-8.

30 Ramirez-Sanchez C, Gonzales F, Buckley M, Biswas B, Henry M, Deschenes MV, et al. Successful treatment of Staphylococcus aureus prosthetic joint infection with bacteriophage therapy. Viruses. 2021 Jun 21;13(6):1182. 
31 Gardner GM, Weiser RS. A bacteriophage for Mycobacterium smegmatis. Proc Soc Exp Biol Med. 1947 Oct;66(1):205.

32 Froman S, Will DW, Bogen E. Bacteriophage active against virulent Mycobacterium tuberculosis. I. Isolation and activity. Am J Public Health Nations Health. 1954 Oct;44(10): 1326-33.

33 Redmond WB, Cater JC. A bacteriophage specific for Mycobacterium tuberculosis, varieties hominis and bovis. Am Rev Respir Dis. 1960 Dec;82:781-6.

34 Baess I. A bacteriophage for subdividing the species M. tuberculosis. Am Rev Respir Dis. 1966 Apr;93(4):622-3.

35 Snider DE, Jones WD, Good RC. The usefulness of phage typing Mycobacterium tuberculosis isolates. Am Rev Respir Dis. 1984 Dec; 130(6):1095-9.

36 Grange JM. Host-phage relationships in the genus Mycobacterium and their clinical significance. Tubercle. 1978 Sep;59(3):203-25.

37 Grange JM, Aber VR, Allen BW, Mitchison DA, Goren MB. The correlation of bacteriophage types of Mycobacterium tuberculosis with guinea-pig virulence and in vitro-indicators of virulence. J Gen Microbiol. 1978 Sep; 108(1):1-7.

38 Grange JM, Aber VR, Allen BW, Mitchison DA, Mikhail JR, McSwiggan DA, et al. Comparison of strains of Mycobacterium tuberculosis from British, Ugandan and Asian immigrant patients: a study in bacteriophage typing, susceptibility to hydrogen peroxide and sensitivity to thiophen-2-carbonic acid hydrazide. Tubercle. 1977 Dec;58(4):207-15.

39 WHO 2020 global tuberculosis report 2020. pdf.

40 Jordan TC, Burnett SH, Carson S, Caruso SM Clase K, DeJong RJ, et al. A broadly implementable research course in phage discovery and genomics for first-year undergraduate students. In: Losick R, editor. mBio. $2014 \mathrm{Feb}$ 4.;5(1):e01051-13.

41 Hatfull GF, Pedulla ML, Jacobs-Sera D, Cichon PM, Foley A, Ford ME, et al. Exploring the mycobacteriophage metaproteome: phage genomics as an educational platform. In: Fraser-Liggett C, editor. PLoS Genet. 2006 Jun 9;2(6):e92.

42 Hatfull GF. Actinobacteriophages: genomics, dynamics, and applications. Annu Rev Virol. 2020 Sep 29;7(1):37-61.

43 Pedulla ML, Ford ME, Houtz JM, Karthikeyan T, Wadsworth C, Lewis JA, et al. Origins of highly mosaic mycobacteriophage genomes. Cell. 2003 Apr;113(2):171-82.

44 Pope WH, Bowman CA, Russell DA, JacobsSera D, Asai DJ, Cresawn SG, et al. Whole genome comparison of a large collection of mycobacteriophages reveals a continuum of phage genetic diversity. ELife. 2015 Apr 28;4:e06416.

45 Azimi T, Mosadegh M, Nasiri MJ, Sabour S, Karimaei S, Nasser A. Phage therapy as a renewed therapeutic approach to mycobacterial infections: a comprehensive review. Infect Drug Resist. 2019 Sep;12:2943-59.
46 Guerrero-Bustamente et al. mBio 2021.pdf.

47 Coscolla M, Copin R, Sutherland J, Gehre F, de Jong B, Owolabi O, et al. M. tuberculosis T cell epitope analysis reveals paucity of antigenic variation and identifies rare variable $\mathrm{TB}$ antigens. Cell Host Microbe. 2015 Nov; 18(5): 538-48.

48 Coscolla M, Gagneux S, Menardo F, Loiseau C, Ruiz-Rodriguez P, Borrell S, et al. Phylogenomics of Mycobacterium africanum reveals a new lineage and a complex evolutionary history. Microb Genom. 2021 Feb 1 [cited 2021 May 14];7(2):000477.

49 Sula L, Sulová J, Stolcpartová M. Therapy of experimental tuberculosis in guinea pigs with mycobacterial phages DS-6A, GR-21 T, My327. Czech Med. 1981;4(4):209-14.

50 Zemskova ZS, Dorozhkova IR. [Pathomorphological assessment of the therapeutic effect of mycobacteriophages in tuberculosis]. Probl Tuberk. 1991;11:63-6.

51 Li P, YongAi L, BaoWen C, YouLun L, XiaoBing $S$, Cheng $S$, et al. Therapeutic effect of bacteriophage D29 in the treatment for guinea pigs infected with sensitive strain of Mycobacterium tuberculosis. Chin J Zoonoses. 2009;25(8):733-6.

52 McNerney R. TB: the return of the phage. A review of fifty years of mycobacteriophage research. Int J Tuberc Lung Dis. 1999 Mar;3(3): 179-84.

53 Hatfull GF. Mycobacteriophages: windows into tuberculosis. In: Miller V, editor. PLoS Pathog. 2014 Mar 20. 10(3):e1003953.

54 Hatfull GF, Vehring R. Respirable bacteriophage aerosols for the prevention and treatment of tuberculosis. In: Hickey AJ, Misra A, Fourie PB, editors. Drug delivery systems for tuberculosis prevention and treatment [Internet]. Chichester, UK: John Wiley \& Sons, Ltd.; 2016 [cited 2021 May 17]. p. 27592.

55 Carrigy NB, Chang RY, Leung SSY, Harrison M, Petrova Z, Pope WH, et al. Anti-tuberculosis bacteriophage D29 delivery with a vibrating mesh nebulizer, jet nebulizer, and soft mist inhaler. Pharm Res. 2017 Oct;34(10): 2084-96.

56 Carrigy NB, Larsen SE, Reese V, Pecor T, Harrison M, Kuehl PJ, et al. Prophylaxis of Mycobacterium tuberculosis $\mathrm{H} 37 \mathrm{Rv}$ infection in a preclinical mouse model via inhalation of nebulized bacteriophage D29. Antimicrob Agents Chemother. 2019 Sep 16;63(12): e00871-19. Epub ahead of print.

57 Dedrick RM, Guerrero-Bustamante CA, Garlena RA, Russell DA, Ford K, Harris K, et al. Engineered bacteriophages for treatment of a patient with a disseminated drug-resistant Mycobacterium abscessus. Nat Med. 2019 May;25(5):730-3.

58 Dedrick RM, Freeman KG, Nguyen JA, Bahadirli-Talbott A, Smith BE, Wu AE, et al. Potent antibody-mediated neutralization limits bacteriophage treatment of a pulmonary Mycobacterium abscessus infection. Nat Med. 2021 Aug [cited 2021 Jul 16];27(8):1357-61.
59 Huh H, Wong S, St Jean J, Slavcev R. Bacteriophage interactions with mammalian tissue: therapeutic applications. Adv Drug Deliv Rev. 2019 May;145:4-17.

60 Dabrowska K, Switała-Jelen K, Opolski A Weber-Dabrowska B, Gorski A. Bacteriophage penetration in vertebrates. J Appl Microbiol. 2005 Jan;98(1):7-13.

61 Abedon ST. Phage therapy of pulmonary infections. Bacteriophage. 2015 Jan 2;5(1): e1020260.

62 Wienhold SM, Lienau J, Witzenrath M. Towards inhaled phage therapy in Western Europe. Viruses. 2019 Mar 23;11(3):295

63 Vandenheuvel D, Singh A, Vandersteegen K, Klumpp J, Lavigne R, Van den Mooter G. Feasibility of spray drying bacteriophages into respirable powders to combat pulmonary bacterial infections. Eur J Pharm Biopharm. 2013 Aug;84(3):578-82.

64 Merril CR, Biswas B, Carlton R, Jensen NC Creed GJ, Zullo S, et al. Long-circulating bacteriophage as antibacterial agents. Proc Nat Acad Sci U S A. 1996 Apr 16;93(8):3188-92.

65 Luong T, Salabarria AC, Roach DR. Phage therapy in the resistance era: where do we stand and where are we going? Clin Ther. 2020 Sep;42(9):1659-80

66 LaVergne S, Hamilton T, Biswas B, Kumaraswamy M, Schooley RT, Wooten D. Phage therapy for a multidrug-resistant acinetobacter baumannii craniectomy site infection. Open Forum Infect Dis. 2018 Apr 1;5(4):ofy064.

67 Dolgin E. The secret social lives of viruses. Nature. 2019 Jun;570(7761):290-2.

68 Akturk E, Oliveira H, Santos SB, Costa S, Kuyumcu S, Melo LDR, et al. Synergistic action of phage and antibiotics: parameters to enhance the killing efficacy against mono and dual-species biofilms. Antibiotics. $2019 \mathrm{Ju}$ 25;8(3):103.

69 Kamal F, Dennis JJ, Elliot MA. Burkholderia cepacia complex phage-antibiotic synergy (PAS): antibiotics stimulate lytic phage activity. Appl Environ Microbiol. 2015 Feb 1; 81(3):1132-8.

70 Labrie SJ, Samson JE, Moineau S. Bacteriophage resistance mechanisms. Nat Rev Microbiol. 2010 May;8(5):317-27.

71 Barsom EK, Hatfull GF. Characterization of Mycobacterium smegmatis gene that confers resistance to phages L5 and D29 when overexpressed. Mol Microbiol. 1996 Jul;21(1):159-70.

72 Barsom EK, Hatfull GF. A putative ABCtransport operon of Mycobacterium smegmatis. Gene. 1997 Jan 31;185(1):127-32.

73 Chen J, Kriakov J, Singh A, Jacobs WR, Besra GS, Bhatt A. Defects in glycopeptidolipid biosynthesis confer phage I3 resistance in Mycobacterium smegmatis. Microbiology. 2009 Dec;155(Pt 12):4050-7.

74 Ramage HR, Connolly LE, Cox JS. Comprehensive functional analysis of Mycobacterium tuberculosis toxin-antitoxin systems: implications for pathogenesis, stress responses, and evolution. In: Rosenberg SM, editor. PLoS Genet. 2009 Dec 11;5(12):e1000767. 
75 United States Environmental Protection Agency. Registration decision for the new active ingredients bacteriophage active against Erwinia amylovora and bacteriophage active against Xanthomonas citri subsp. citri. [Internet]. 2018. Available from: https://www. regulations.gov/document/EPA-HQOPP-2017-0678-0007.

$76 \mathrm{Mu}$ A, McDonald D, Jarmusch AK, Martino C, Brennan C, Bryant M, et al. Assessment of the microbiome during bacteriophage therapy in combination with systemic antibiotics to treat a case of Staphylococcal device infection. Microbiome. 2021 Dec;9(1):92.

77 Loc-Carrillo C, Abedon ST. Pros and cons of phage therapy. Bacteriophage. 2011 Mar; 1(2): 111-4.

78 Gordillo Altamirano FL, Barr JJ. Phage therapy in the postantibiotic era. Clin Microbiol Rev. 2019 Jan 16;32(2):e00066-18.

79 Duplessis C, Biswas B, Hanisch B, Perkins M, Henry M, Quinones J, et al. Refractory Pseudomonas bacteremia in a 2-year-old sterilized by bacteriophage therapy. J Pediatric Infect Dis Soc. 2018 Aug 17;7(3):253-6.

80 Majewska J, Kaźmierczak Z, Lahutta K, Lecion D, Szymczak A, Miernikiewicz P, et al. Induction of phage-specific antibodies by two therapeutic Staphylococcal bacteriophages administered per os. Front Immunol. 2019 Nov 14;10:2607.

81 Żaczek M, Łusiak-Szelachowska M, JończykMatysiak E, Weber-Dąbrowska B, Międzybrodzki R, Owczarek B, et al. Antibody production in response to Staphylococcal MS-1 phage cocktail in patients undergoing phage therapy. Front Microbiol. 2016 Oct 24 [cited 2021 Apr 3];7:1681.
82 Pelfrene E, Sebris Z, Cavaleri M. Comment on Fauconnier, A. Phage therapy regulation: from night to dawn. Viruses. 2019 Aug 22;11(9):771.

83 Górski A, Międzybrodzki R, Łobocka M, Głowacka-Rutkowska A, Bednarek A, Borysowski J, et al. Phage therapy: what have we learned? Viruses. 2018 May 28;10(6):288.

84 Pelfrene E, Botgros R, Cavaleri M. Antimicrobial multidrug resistance in the era of COVID-19: a forgotten plight? Antimicrob Resist Infect Control. 2021 Dec;10(1):21.

85 Pelfrene E, Willebrand E, Cavaleiro Sanches A, Sebris Z, Cavaleri M. Bacteriophage therapy: a regulatory perspective. J Antimicrob Chemother. 2016 Aug;71(8):2071-4.

86 Schmidt C. Phage therapy's latest makeover. Nat Biotechnol. 2019 Jun;37(6):581-6.

87 Ferry T, Kolenda C, Batailler C, Gustave CA, Lustig S, Malatray M, et al. Phage therapy as adjuvant to conservative surgery and antibiotics to salvage patients with relapsing S. aureus prosthetic knee infection. Front Med. 2020;7:570572.

88 Centre Hospitalier Universitaire de Nīmes. Comparison of the efficacy of standard treatment associated with phage therapy versus standard treatment plus placebo for diabetic foot ulcers monoinfected by Staphylococcus Aureus: a randomized, multi-centre, controlled, 2-parallel-group, double-blind, superiority trial [Internet]. 2020 Jul clinicaltrials. gov; [cited 2021 May 13]. Report No.: NCT02664740. Available from: https://clinicaltrials.gov/ct2/show/NCT02664740.

89 Armata Pharmaceuticals, Inc. A phase $1 b / 2 a$, multi-center, double-blind, randomized, placebo-controlled, single and multiple ascending dose study to evaluate the safety and toler- ability of AP-PA02 multi-phage therapeutic candidate for inhalation in subjects with cystic fibrosis and chronic pulmonary Pseudomonas aeruginosa $(\mathrm{Pa})$ infection [Internet]. $2021 \mathrm{Apr}$ clinicaltrials.gov; [cited 2021 May 13]. Report No.: NCT04596319. Available from: https:// clinicaltrials.gov/ct2/show/NCT04596319.

90 Harper DR. Criteria for selecting suitable infectious diseases for phage therapy. Viruses. 2018 Apr 5;10(4):177.

91 Guerrero-Bustamante CA, Dedrick RM, Garlena RA, Russell DA, Hatfull GF. Toward a phage cocktail for tuberculosis: susceptibility and tuberculocidal action of mycobacteriophages against diverse Mycobacterium tuberculosis strains. mBio. 2021 May 20;12(3): e00973-21.

92 Abedon ST. Phage-antibiotic combination treatments: antagonistic impacts of antibiotics on the pharmacodynamics of phage therapy? Antibiotics. 2019 Oct 11;8(4):182.

93 Broxmeyer L, Sosnowska D, Miltner E, Chacón $\mathrm{O}$, Wagner D, McGarvey J, et al. Killing of Mycobacterium avium and Mycobacterium tuberculosis by a mycobacteriophage delivered by a nonvirulent mycobacterium: a model for phage therapy of intracellular bacterial pathogens. J Infect Dis. 2002 Oct 15;186(8):1155-60.

94 Nieth A, Verseux C, Barnert S, Süss R, Römer $\mathrm{W}$. A first step toward liposome-mediated intracellular bacteriophage therapy. Expert Opin Drug Deliv. 2015 Sep 2;12(9):1411-24.

95 Singla S, Harjai K, Katare OP, Chhibber S. Encapsulation of bacteriophage in liposome accentuates its entry in to macrophage and shields it from neutralizing antibodies. In: Bengoechea JA, editor. PLoS One. 2016 Apr 26;11(4):e0153777. 